consumer anywhere in the EU. Apple is therefore encouraging every major record label to take a pan-European view of pricing, promising to reconsider its continuing relationship in the UK with any record label that does not lower its wholesale prices in the UK to the panEuropean level within six months.

\title{
Living in harmony
}

Apple's agreement with the Commission means that UK consumers will soon pay the same for music downloads from iTunes as customers from the Eurozone. Which? has welcomed the agreement as 'music to the ears of UK iTunes customers' and Apple's decision shows how the work of the Commission can benefit consumers in the UK.

Simon Albert, Associate, EU \& Competition

simon.albert@blplaw.com

\section{E-commerce: Europe gets behind online content businesses}

\section{Vanessa Barnett}

Journal of Direct, Data and Digital Marketing Practice (2008) 9, 391-392. doi:10.1057/dddmp.2008.12

The Commission has adopted a 'Communication on Creative Content Online' designed to support the development of innovative business models and encourage cross-border delivery of online content.

\section{Areas of concern}

\section{Areas of concern}

In its communication, the Commission has identified four key areas of concern:

- Availability of content: in what the Commission considers to be a 'nascent market' there are concerns that settling terms of trade for exploitation is difficult, and bundling, exclusivity and nonuse of media rights may need addressing.

- Multi-territory licensing of content: the lack of multi-territory copyright licences makes it difficult for online services to fully benefit from the internal market potential and there is a need to improve this.

- Interoperability and transparency of Digital Rights Management (DRM) systems: as yet there are no interoperable DRM solutions and there is a need to set a framework for transparency of DRM interoperability with proper consumer information with regard to usage restrictions. 


\section{Action points}

- Legal offers and piracy: the Commission sees piracy and unauthorised up- and downloading of copyrighted content as 'a central concern' and considers it right to instigate cooperation procedures between access/service providers, right holders and consumers in order to ensure a wide online offer of attractive content, consumer-friendly online services, adequate protection of copyrighted works, awareness raising/education on the importance of copyright for the availability of content and close cooperation to fight piracy/unauthorised file-sharing.

\section{Areas of action}

To start to address these areas of concern, the Commission:

- launched a public consultation with 11 questions relating to: transparency (labelling) of DRM systems; encouragement of innovative licensing regimes; legal offers and piracy

- announced that it will create a stakeholders' discussion and cooperation platform (to be called the Content Online Platform) devoted to content-specific or cross-industry negotiations, for example those relating to availability of content, improvement of rights clearance mechanisms, development of multi-territory licensing, management of copyright online and cooperation mechanisms to improve respect of copyright in the online world.

\section{Commentary}

Wherever you sit in the online content food chain — rights owner, aggregator, distributor - we would encourage you to participate: online content is a growth area with significant revenue streams at many levels. Even as a user these issues should not go unnoticed - the Content Online Platform also envisages producing a guide for business and consumer users.

Vanessa Barnett, Associate, Business \& Technology Services vanessa.barnett@blplaw.com

\section{Digital proposals to legalise private copying}

\author{
Ian De Freitas
}

Journal of Direct, Data and Digital Marketing Practice (2008) 9, 392-394. doi:10.1057/dddmp.2008.13

The government has launched a consultation on proposals to legalise personal copying by consumers. These proposals risk causing 